Lianne Koren

\title{
A Mysterious Collection: Musings on Archival Power and Historical Vulnerability
}




\section{First Impressions}

Sitting in the Jewish Public Library Archives, I held in my hands a bundle of envelopes, each with a photograph. The images had once been part of a photo album that had since been dismantled. All that was left of the album was a heap of papers and photos cut out of their contexts to preserve them. What once was a coherent whole was now a mangled mix of memories and images. I start with a confession: as I gingerly opened each envelope and saw the dozens of photographs of Yemenite Jews on their journey from Aden to Israel, they felt familiar to me. My own Jewish Yemenite heritage made me feel like I was part of this story. He could have been my great-grandfather, I thought to myself. She looks like my dodah. ${ }^{.}$That young girl could have been my sister. Their faces held my attention. They made me feel like I was no longer in the basement of the JPL rummaging through the archives. Instead, I was in my grandmother's kitchen flipping through images of people and of days that were part of me.

The portraits of three young women (depicted below) forced me to pause. Their gazes mesmerized me as soon as I saw them. I desperately wanted to meet these women, to talk to them. I wanted to know more. Not only could I see them, but they too could see me. In that brief moment when you first look at an image, you are carried to a different place. When that image is a portrait, you are also brought into a relationship with its subject. The photographer Leni Sonnenfeldreflects on the power of eyes to communicate; that "talking eye." She writes that she rarely spoke the language of the people she photographed but she insists that "eyes spoke to each other [... T They have a language of their own."3 Like Sonnenfeld, I felt as though I understood these young women through their eyes; as though their stories, their joys and their hardships could be revealed by the freezing of a moment. Yet the greatest strength in photography-its immediacy, the intimacy between viewer and subject, the feeling that a story is being told even when all its actors are silent-is also its greatest weakness.

Through this snapshot of the lives of these three young women, I felt like I understood them, as though I could truly share in their experiences through their expressions. While I agree with Sonnenfeld that eyes are revealing, I must disagree with her in her insistence that they are able to communicate without language, without voice. These women are silent. I do not know them. I do not know their names. While I can look at their eyes, I cannot see into them or through them. The gaze of these women does not reveal their inner workings nor divulge their impressions and perceptions. 


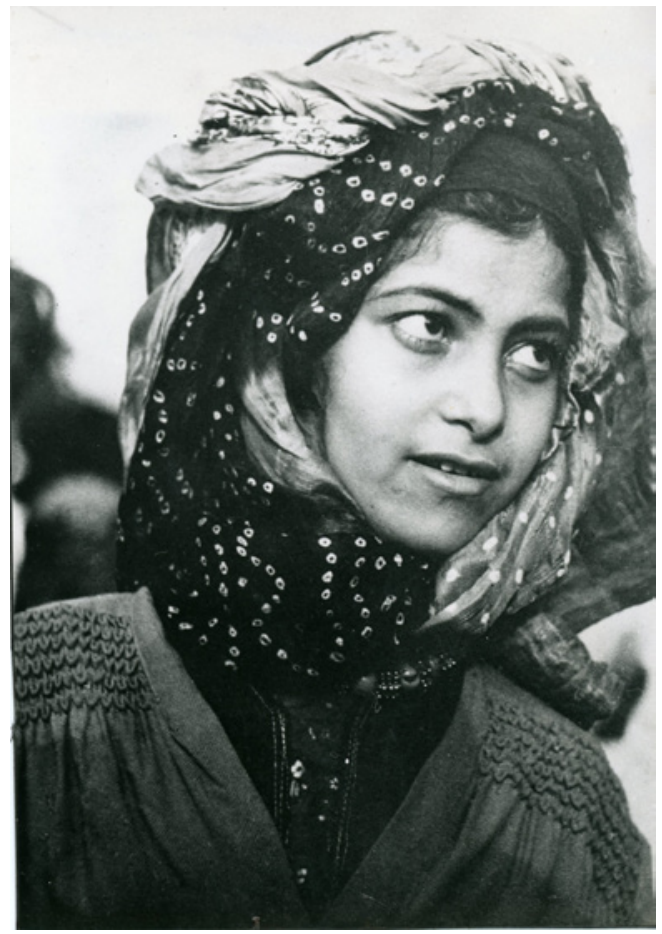

Three Portraits of Young Yemenite Women

1397_010. Abraham Rother Fonds \#1397 (1940-1960), Jewish Public Library Archives. 1397_001-1397_032.

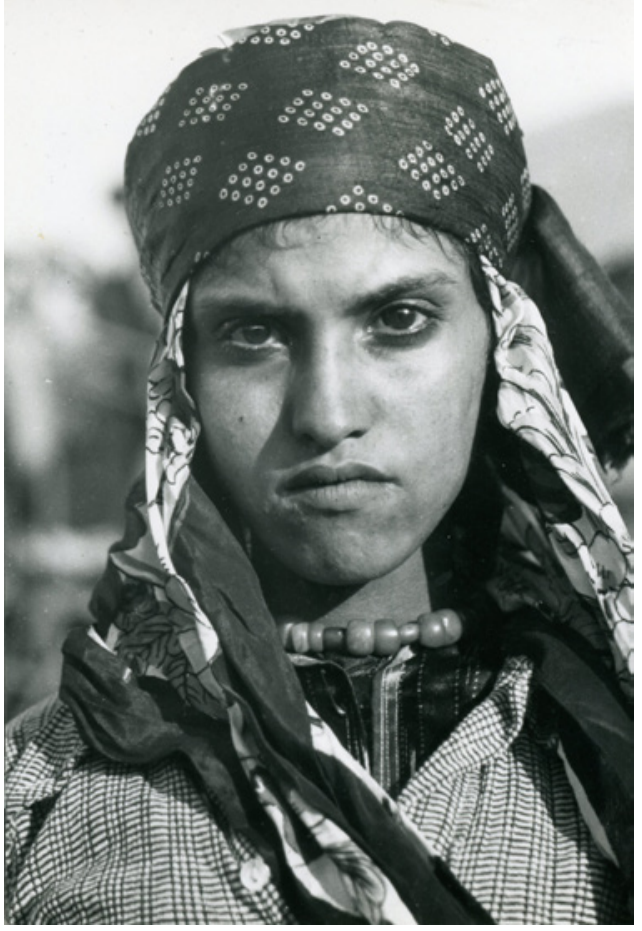




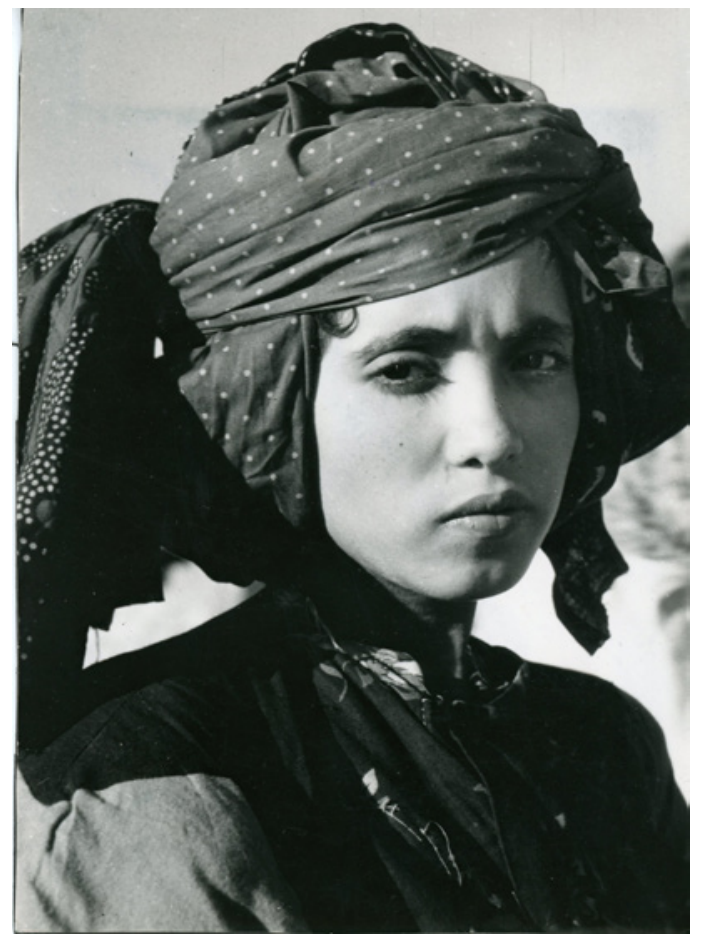

1397_031. Abraham Rother Fonds \#1397 (1940-1960), Jewish Public Library Archives. 1397_001-1397_032.

\section{The Album}

The album belonged to Jewish Montrealer Abraham Rother and is part of the JPL's Abraham Rother Fonds. The archival box contains snippets of the lives of the Rother family. Wedding invitations and menus are kept. There are certificates attesting to an animal hunt and souvenirs of various adventures. There are also newspaper clippings mentioning the Rothers. An important feature of the collection is the record of Abraham's travel habits. He was clearly an avid traveller. Most impressive is the record of a year-long world tour in 1956 which included visits to San Francisco, Honolulu, Tokyo, Hong Kong, Bangkok, New Delhi, Rome, and many other places. However, the most significant part of the Abraham Rother Fonds is the family photo album. In nearly every way, the collection comes across as a run-of-the-mill family album. The photographs feature formal portraits of family members, as well as pictures of friends and family sitting on the couch or around the dinner table. It documents family gatherings for Shabbat, Bar Mitzvahs and weddings. ${ }^{4}$ Pictures of holidays and hunting trips also make an appearance.

Within this personal album, the thirty-two photographs in question vary much in tone and appearance. They depict barefoot women carrying large pots on their heads, a man crouched next to his nargilah, men reading and holding the Torah, and 
groups of people, including huddled families next to airplanes or inside them. Above all, there are individual portraits: of women with their heads covered, of men in kippot, of mothers and their babies, and of children and the elderly with their expressive faces. The dark complexions of those depicted, the traditional Yemenite clothing, the desert, the bell tents and the airplanes make up an idealized portrait of the Yemenite immigration to Israel. Between 1948 and 1950, the vast majority of the Jewish population in Yemen-approximately 50,000 people-were airlifted out of the British Crown Colony of Aden and brought to the nascent State of Israel..$^{5}$ The Joint Distribution Committee (known as both the JDC and "The Joint") was given full control over the orchestration of the migration effort, with the support of the Israeli government and the Jewish Agency. ${ }^{6}$ Dubbed "Operation Magic Carpet" or "Operation on Eagles' Wings,"7 the almost complete transplantation of the Yemenite community to Israel "was the first mass immigration of Jews from an Islamic country."

Apart from the "Operation Magic Carpet" tag in the digital archive and a distinct ethnic Yemenite look, the collection contains no other information on the photographs. It is unclear precisely when and where the photographs were taken, who took them and for what purpose. Even more mysterious than the content of the images is their provenance. How did professional photos of a historic event in the Jewish world end up in a private photo album of an affluent Montreal Ashkenazi family?9

\section{The Operation: A Mythology}

In the Road to Redemption, Tudor Parfitt traces the conventional imagining of Yemenite Jews upon hearing the news of Israeli statehood: "these 'primitive' 'Messiah-haunted Jews' assumed that the Messiah had come and dropping everything had flocked barefoot to Aden where, astounded by every smallest manifestation of the modern world, they waited to be taken up 'on wings of eagles' to Eretz Yisrael."10 In the same vein, Esther Meir-Glitzenstein writes that the aliya was "described as having brought relief and deliverance to Yemenite Jewry and it is also perceived as a daring, miraculous, even cosmic event in which the Yemenite Jews were rescued in the blink of an eye from a distressed country and taken by their saviors from a backwards, traditional society to a modern, progressive society."

The mythology surrounding the Yemenite migration was being constructed as soon as the first media release. The journalist who broke the story was Ruth Gruber, who was among the first correspondents allowed to fly in the airlift. In an article published in the New York Herald Tribune on November 7, 1949, Gruber writes:

In an exodus not unlike that from Egypt 3,000 years ago, between 40,000 and 50,000 Jews of the Yemen have been pouring into the British Protectorate of Aden and from there are being flown to Israel on an all-American air 
lift. Giant silver-winged American-built C-54 Skymasters, flown by American pilots, some wearing cowboy boots from Texas, have been flying I,60o miles non-stop from Aden to Israel, transporting Yemenite Jews wearing long robes, silver fringed hoods, prayer shawls and lovelocks, looking like people of the Bible... ${ }^{\text {I2 }}$

Gruber's account presents an encounter between civilization and savagery-or of American strength versus Arab weakness. It is important to note, as Meir-Glitzenstein points out, that Ruth Gruber had been brought to Aden by the JDC and her article was published in coordination with the organization.

Meir-Glitzenstein explains that what is truly exceptional about the JDC'S release of the story was its exclusions. The release did not mention the state of health of the Yemenites nor the living conditions in the transit camp in Aden. ${ }^{13}$ Only three days prior to the publication of Gruber's story, on the $4^{\text {th }}$ of November 1949, the Jewish Emergency Committee in Aden was so concerned at what was happening at Hashed [the JDC-run transit camp] that they cabled the Joint offices in Paris to complain that "the maladministration (sic) of Hashed Camp has resulted in scores of deaths and misuse of public funds." Moreover, two internal commissions of inquiry were looking into the administration of the camp, and the decision had already been made to replace the camp director. ${ }^{14}$

However, the announcement by the JDC professed that Yemenite Jews were greeted by "a gigantic reception centre about ten miles outside of Aden city. Here they have been fed and cared for by the JDC in cooperation with the Jewish Agency. A staff of some 70 doctors, nurses, clerks and cooks, both American and Israelis, serve in the camp at the present time."' ${ }^{{ }_{15}}$ This was a far cry from the truth.

Meir-Glitzenstein underscores the sheer tragedy of the migration. She remarks that by the summer of 1949, "hundreds of people lost their lives en route to Israel and the vast majority of the survivors arrived in poor health." ${ }^{{ }^{16}}$ Moreover, the Hashed camp had its own death toll: one list counts 429 deaths at Hashed, the place where refugees "were supposed to find food and medical treatment after their long way from Yemen., ${ }^{17}$ Between July and November 1949, "Most of the 30,000 immigrants who arrived in Israel [. . . s suffered from hunger and diseases, including 3,000 children who needed urgent hospitalization that the new state was not able to provide." ${ }^{\prime 18}$ As if the conditions were not bad enough, the staffs' treatment of the refugees was also concerning. Parfitt likens their treatment of the Yemenite refugees in the Hashed camp with the colonial attitude of the British towards "natives." He argues that Jewish personnel in the Aden camps had frequently treated the Yemenites with a lack of dignity and with minimal concern for their traditional social structures. ${ }^{19}$ Parfitt even notes that some staff members were accused of physically abusing refugees 
with sticks or fists. ${ }^{20}$ Yosef Zadok, a Yemenite Jew who had migrated to Israel earlier and was assisting with the migration effort, also accused the staff of "cruelty, incompetence and arrogance in their treatment of the Yemenites."21

However, the Rother series depicts the myth and not the reality. For example, in figure 4 smiling people are going about their daily chores (fig. 4). The women are wearing traditional Yemenite garb. A tap is visible, implying that the needs of the camp residents are cared for. While their environment seems hardly luxurious, it appears decent. Of the entire series, figure 5 is the only image where living quarters are visible. This photo provides some indication of the actual conditions of camp life but only just. The image functions as a generic depiction of a refugee camp with the bell tents against a desert backdrop. Very little else is revealed. While being the starkest image in the album, it still implies a decent standard of living. The sitting man appears to be cutting his nails. He has shoes and somewhere to dry his clothes, assuming a vast improvement in living standards relative to those without shelter on the camp's outskirts.

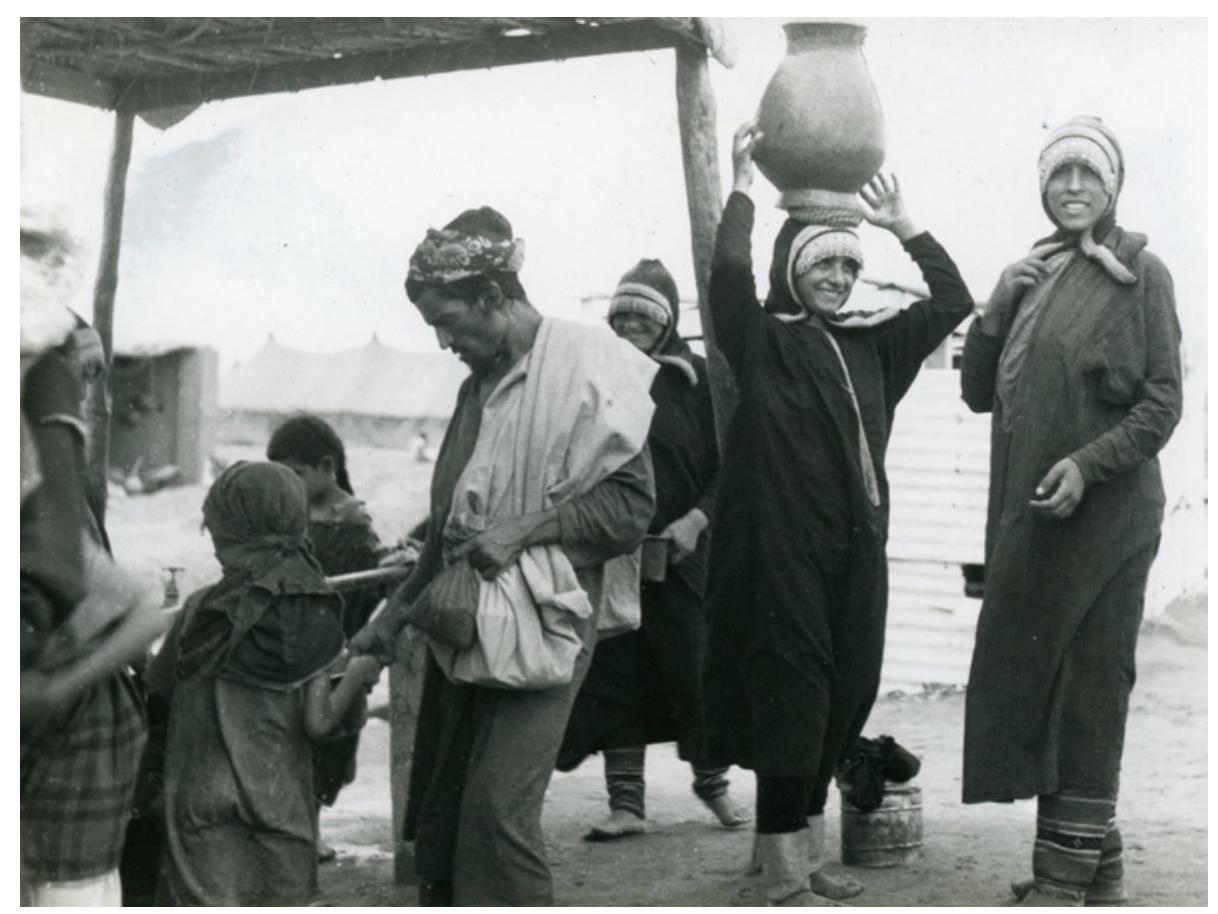

Group of Yemenites Gathered Around Water Tap,

1397_028. Abraham Rother Fonds \#1397 (1940-1960), Jewish Public Library Archives. 1397_001-1397_032. 


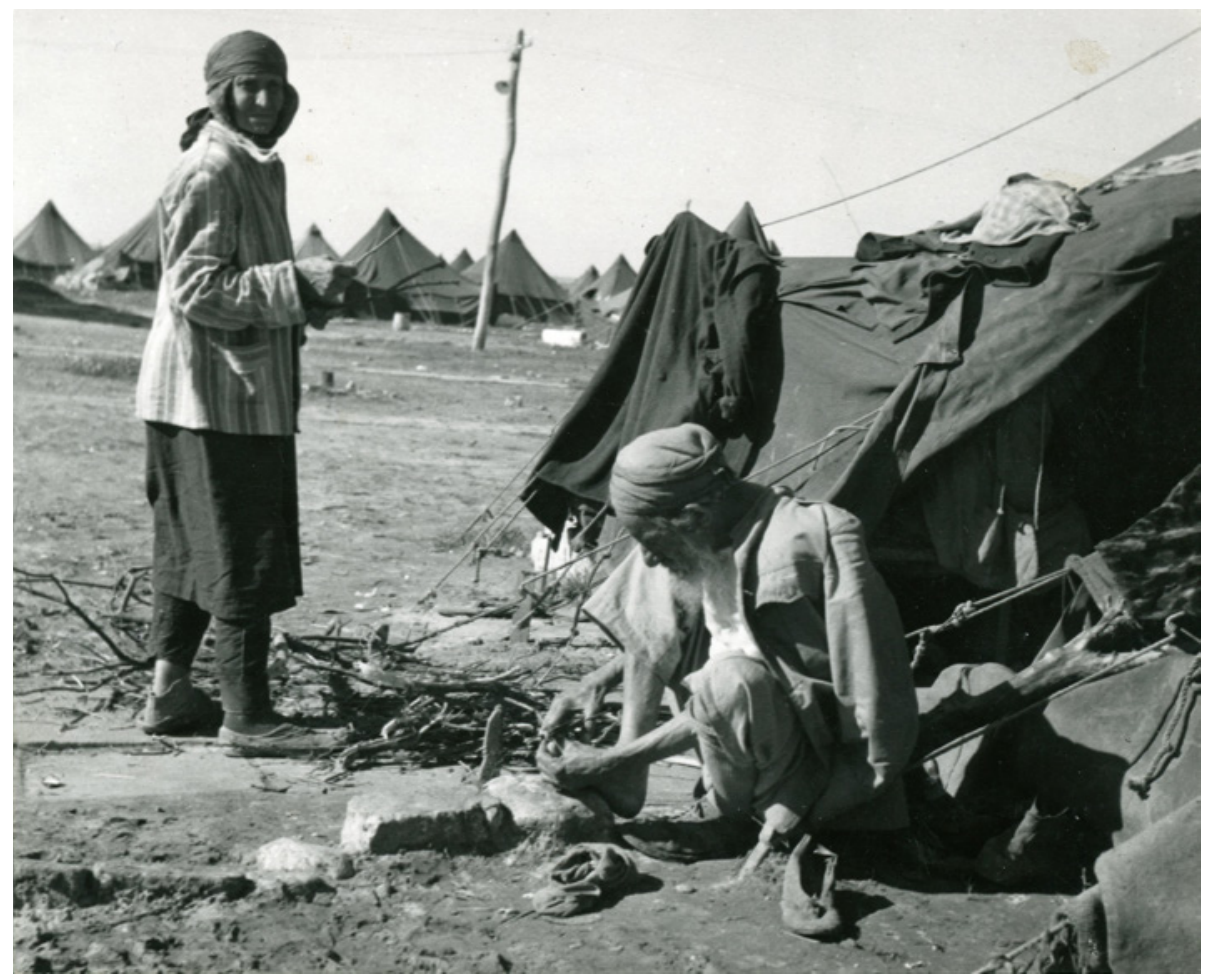

Yemenite Man Sits Outside Tent

1397_022. Abraham Rother Fonds \#1397 (1940-1960), Jewish Public Library Archives. 1397_001-1397_032.

Noa Hazan describes how Yemenite bodies have been racialized through photography. ${ }^{22}$ Hazan explains that hygiene is used as a signifier of modernity and civilization. The visuals of people who are barefoot and dirty feeds a narrative of the Yemenite as unhygienic which "indicates faulty morals, lack of culture and a generally degenerate state"23 Further, photographs of Eastern women emphasize their otherness "by the colour of her skin, her attire and the way she goes about her daily tasks."24 All these serve to oppose the supposed backwardness of Yemenite culture to that of a modern Israel, enabling a "racial perception to travel freely from the photographs to the viewers." 25 Put another way, "the hygiene designator serves to present the 'otherness' of the photographed and to erect a separation between 'them' and 'us' the viewers."26 Photographs of the Yemenites tend to reinforce the notion that Eastern culture is a "treasure of the past" and Eastern people are "primitives who did not update their customs." ${ }^{27}$ In Figure 6, a Yemenite woman is standing barefoot on the sand. The act of her carrying a large pot on her head buttresses the notion that the Yemenites engage in daily tasks in a backward fashion. Equally, Figure 7 features four women in traditional clothing further promulgating the view that Eastern culture is from a bygone era, and that these women are not "modern." 


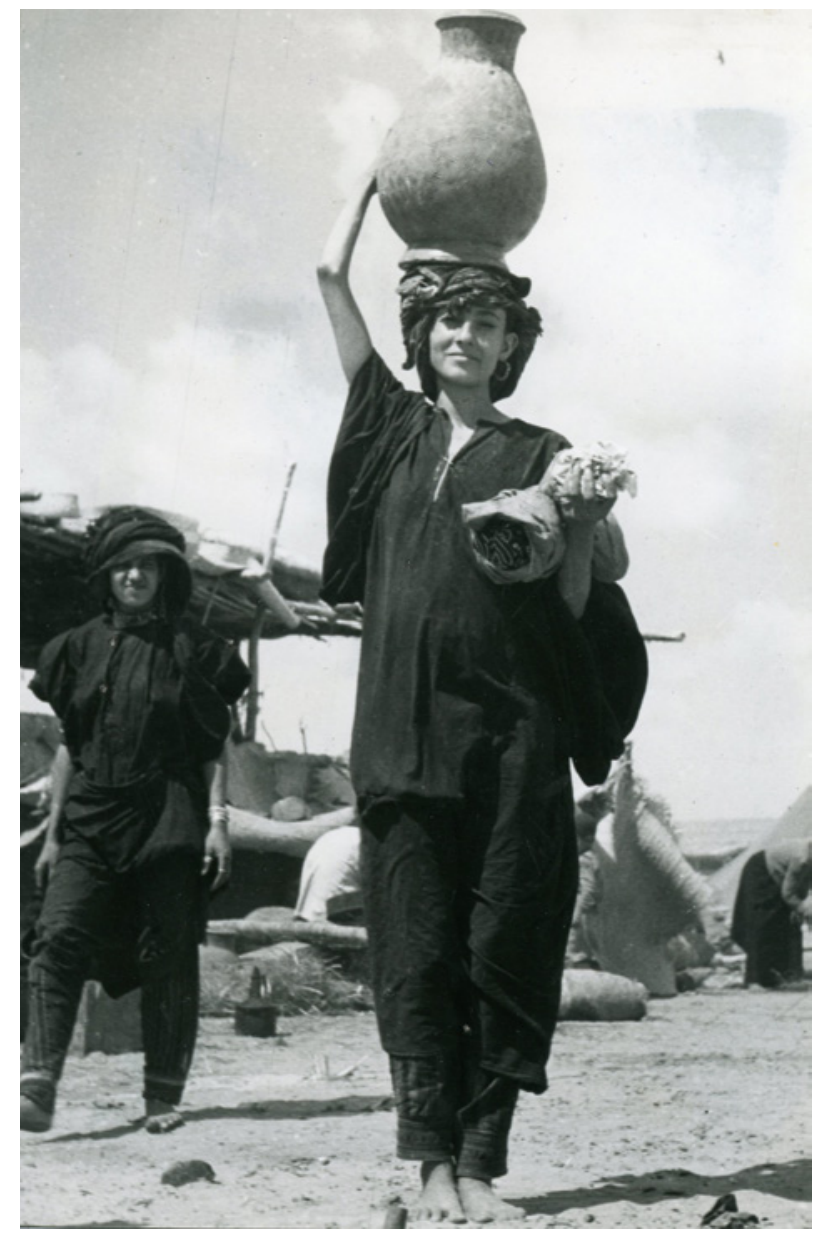

Portrait of a Yemenite Woman

1397_013. Abraham Rother Fonds \#1397 (1940-1960), Jewish Public Library Archives. 1397_001-1397_032.

The photographs in the Rother album represent "Operation Magic Carpet" in an acutely mythologized and stereotyped form. The notable absence of images of hardship related to migration, the depiction of the Yemenite Jews as "traditional" in contrast to "modern" and "Western," and the vision of the migrants as exilic and de-historicized refugees all fuel the mythology. The photographs, without context and interpretation, reiterate the power, dominance and modernity of the State of Israel and cast the Yemenites as ignorant and primitive Jews. Given this framing of the images, it seemed likely that the photographs were commissioned either by the JDC or the State of Israel. 


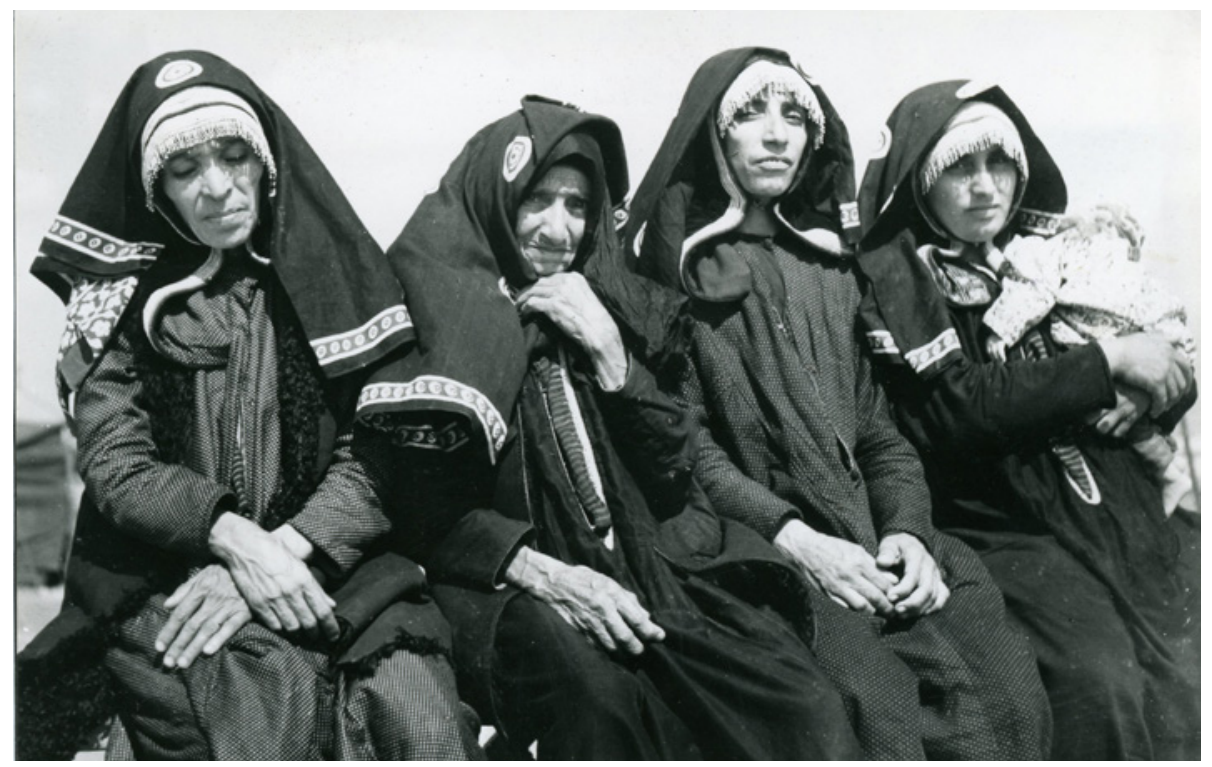

Four Yemenite Women and a Baby in Traditional Dress

1397_021. Abraham Rother Fonds \#1397 (1940-1960), Jewish Public Library Archives. 1397_001-1397_032.

\section{The Archive}

Archival and heritage institutions tend to present themselves as objective and dispassionate entities. The mandate of the JPL archives is "to collect, preserve, and make available the social, economic, and cultural accomplishments of Montreal's Jewish community using original documents, photographs and recordings." ${ }^{28}$ However, archival collection and preservation are activities laden with meaning. The archive, while presenting itself as neutral and detached, is in reality formed by people who created the material, deposited it, or collected and preserved it. This is an inherently subjective and idiosyncratic process. The researchers and investigators who engage with archival material further contribute to its afterlife and are part of a long process that evaluates worthiness and that engages with a long-established power play.

Ann Laura Stoler in Along the Archival Grain: Epistemic Anxieties and Colonial Common Sense explores "archiving-as-process rather than archives-as-things." ${ }^{29}$ An archive is a corpus of writing but she also describes it as a "force field that animates political energies and expertise, that pulls on some 'social facts' and converts them into qualified knowledge, that attends to some ways of knowing while repelling and refusing others." ${ }^{30}$ Stoler's notion of archiving-as-process is a recognition that "facts" are created, but they are also in conversation with each other. In other words, archives are an ethnographic space "where truth claims compete." ${ }^{\text {I }}$ Stoler's title flouts the 
historian's logic to read "against the grain." Rather, she encourages scholars to read along the grain. By this, Stoler asks us to be attentive to processes of production and acknowledge the power of archives to create, to sequester and to rearrange. ${ }^{32}$ Stoler's discussion shifts the focus from "archive-as-source" to "archive-as-subject." ${ }^{33}$ By seeing the institution of the archive as a worthy subject in its own right, the politics of knowledge as well the creation and solidification of historical narratives come into sharper focus. Questions such as "what counts as knowledge and who is in power to record their versions of it has since become a founding principle of colonial ethnography," and equally deserves to be posed in the archival context. ${ }^{34}$ Stoler calls for a methodological shift: rather than seeing archival work as extractive, it should instead be viewed as an ethnographic exercise..$^{35}$ Stoler explains her call as "a methodological commitment to how history's exclusions are secured and made." ${ }^{36}$

Like Stoler, Michel-Ralph Trouillot in Silencing the Past: Power and the Production of History also speaks to questions of inclusion and exclusion in historical inquiry. Instead of tasking himself with discerning what history is, Trouillot articulates "how history works." ${ }^{37} \mathrm{He}$ is concerned with how silences are produced and maintained in historical narratives. He contends that absences and silences are not only unavoidable byproducts of historical inquiry but are in fact a fundamental part of the historical process:

Silences are inherent in history because any single event enters history with some of its constituting parts missing. [...] There is no perfect closure of any event, however, one chooses to define the boundaries of that event. Thus whatever becomes fact does so with its own inborn absences, specific to its production..$^{38}$

Trouillot draws attention to the double entendre of the word "history" as both process and narrative. He explains that history is both "what happened' and 'that which is said to have happened." 39 Through a focus on "process and conditions of [historical] production," it is possible to discern how the two meanings of history intermingle by understanding "the differential exercise of power that makes some narratives possible and silences others." ${ }^{40}$ In other words, the difference between "what happened" and "that which is said to have happened" is primarily about power. Trouillot argues that power is not a singular force that exerts one definitive influence; rather it is constitutive of each historical moment-the moment of fact creation, of fact assembly, of fact retrieval and of retrospective significance. ${ }^{41}$ The last three moments implicate the archive. Historical "facts" and their narratives solidify as each moment builds upon the former. Trouillot argues that "Archives set up both the substantive and formal elements of the narrative. They are the institutionalized sites of mediation between the sociohistorical process and the narrative about that process." ${ }^{42}$ The archival process sets up the "facts" that contribute to the mythology of "Operation Magic Carpet." 
The archive-along with the JDC and Israel-presents us with a portrait of "Operation Magic Carpet" that begins and ends with a tarmac. This is part of the silencing process. Everything in between: the journey from Yemen, the situation in the transit camps, and the complicated assimilation when the plane lands are left out of the story. Yet the airplanes and the moments directly before take-off and after landing are the heart of the story. The decontextualized nature of the photos reinforces the notion that images can speak for themselves. Even the archival "tag" labelling the event "Operation Magic Carpet" glamorizes the migration and ignores the tremendous human cost of the operation.

\section{Investigating Provenance}

I searched the Joint Distribution Committee's online archives hoping for doubles of the photographs in the Rother album. ${ }^{43}$ After scouring their entire online collection (which represent all their archival holdings), I found two matches: a portrait of a young woman and of a man. The JDC's listing of the images provides some crucial information. The image of the young girl is dated to "cr949," and is marked to have been taken in Aden. The image is entitled, "Yemenite girl; Operation Magic Carpet" and the description reads, "Yemenite girl about to board airplane; also see wide shot-NY_I4765." ${ }^{\prime 4}$ The wider shot is not present in the Rother album. The JDC archive also provides the name of the photographer, "Al Taylor." ${ }^{45}$ Similarly, the portrait of the man is dated "I948-1949," but it was taken at the Lydda Airport in Israel. It is entitled: "A Yemenite man who has just arrived in Israel on Operation Magic Carpet." The photo is attributed simply to "Photo Sternberg." Unlike the portrait of the young girl which is an exact replica of the photograph in the album, the man's photo in the Rother album is a cropped and tilted version of the image found in the JDC archive.

The matching photos raise more questions than they answer. Can we attribute the collection to Alexander Taylor, to Sternberg, to both or to an even larger group of photographers? Yet it seems likely that most of the photos should be attributed to Alexander (Al) Taylor. The JDC archive contains a total of ten photos by Sternberg, whereas Taylor's photographs go into the hundreds. Taylor was also officially employed by the JDC for over three decades as a photographer and a public relations representative. ${ }^{46}$ According to the JDC website:

JDC's Al Taylor photo collection is primarily from the post-World War II period and focuses on three main regions of the Jewish world: Europe, the Middle East, and North Africa. He covered major events and developments in twentieth-century Jewish-and JDC-history, such as Jewish life in North Africa, Operation Magic Carpet from Yemen, and the Displaced Persons (DP) camps in Europe. ${ }^{47}$ 
From the JDC's large holdings of Taylor's photographs, his role as a JDC employee and the credit that the JDC ascribes to him, it is likely that he was the principal photographer for "Operation Magic Carpet." Al Taylor's connection to the JDC reveals that the photographs should be analyzed primarily as private commissions. Having orchestrated the migration effort, the JDC had a vested interest in constructing the vision of the journey to Israel from Yemen as efficient, speedy, and above all miraculous.

A burning question remains: how did professionals-likely JDC commissioned photographs - end up in the private family photo album of the Jewish Montrealer Abraham Rother? Is there a link between Taylor and Rother? While I cannot pretend to know the answer, a few possibilities exist. A potential clue is found in Thomas Fensch's Oskar Schindler and His List: The Man, The Book, The Film, The Holocaust and Its Survivor ${ }^{4}$. Al Taylor is highlighted as the photographer for an important event: Herbert Steinhouse's Friday night party in January of 1949 that reunited Oskar Schindler with all the Paris schindlerjuden..$^{49}$ Fensch notes that Steinhouse and Al Taylor were old friends. ${ }^{50} \mathrm{Al}$ Taylor's friendship with Herbert Steinhouse connects Taylor to the Montreal Jewish Community. Like the Rothers, Steinhouse lived in Westmount with his wife. ${ }^{.1}$ They were both active in Montreal's tight-knit elite Jewish community..$^{52}$

The potential connection between Taylor, Steinhouse and the Rothers-though this is all speculation-speaks to the piecemeal way that history is constructed. The picture that emerges of the photos' provenance is one in which powerful men pass around photos of Jewish interest. What meaning did the photographs hold for these men? Perhaps the Rothers' interest in travel made them inclined to be curious about all things "exotic." Maybe their Jewish heritage made them feel connected to the larger Jewish project of the "ingathering of the exiles" or they simply felt connected to their co-religionists. It is also possible that the Rothers donated to the migration effort and received the photographs from the organization as recognition for their donation. However, the JDC's policy in pre-internet years was to annually distribute JDC photos to Jewish organizations, not to individuals. Even more suspect, the JDC does not have the photos in the Rother album. Why are the remaining thirty photos in the Rother album absent from the JDC's collection? The portrait of the man was cropped and tilted: does this imply that Rother's collection was tailored for him? Were the photos purchased? Were the Rothers personally involved in the effort? Regardless of how the photographs landed in the hands of the Rothers, I remain baffled as to why they would be placed alongside intimate family photos. Does this imply the Rothers felt a personal attachment to the images? The answers remain a mystery.

\section{A Second Impression}

Sonnenfeld believes that eyes have a language of their own. I have come to believe that silence is a language of its own. Silence has a way of communicating and con- 
veying information without acknowledging that it is doing so. We respond to what is present, to what is tangible, to what visibly exists. I can hold the photographs in my hand. They are real. They show me something I can immediately and instinctually respond to. The photographs tell me about "Operation Magic Carpet": the unbelievable and magical effort in which Jews flocked desperately to Aden from all over Yemen, full of religious zeal and hope. They were embraced by the JDC before being sent on the wings of eagles to the land of milk and honey. The silences of the archival record and the absence of context propel this vision forward. Without certainty over who took the photographs, for what purpose and for whose use, the photos can only, literally, speak for themselves. Moreover, the archive further reinforces the silence of the photograph's subjects; they are muted by the archival process that does not grant them historical context. The mythology of the migration and the vision of Yemenite Jews is constructed not only by the images themselves but is also reinforced by archival practices. When the photographs are reinserted into the history of the Yemenite emigration - taking into account the painful journey to Aden, the abysmal conditions of camp life, the mismanagement and poor treatment by the JDC staff, and the long wait periods before flying-, they reveal a very different story. The photographs are part of the mythology created by the JDC and the State of Israel to advance the perception of Jewish and Israeli strength and unity. This mythology disguises a difficult lived reality.

The meaning of the photographs has completely changed before my eyes, over the course of researching and writing about them. When I first opened each envelope, the photographs initially filled me with a sense of intimacy and familiarity. I saw the gaze of the photo's subjects as informative. They felt emotionally revealing. However, what was captured in photographic clarity was also clouded in symbolism and ideology. The photographs represent many things: "Operation Magic Carpet," Israeli nationality, the effectiveness of Jewish organizations, and backward Eastern culture. Ironically, the photographs seem to represent everything about Jewish Yemenites and their migration to Israel and yet, reveal nothing about the individuals during their journey. Hazan writes, "The act of seeing in itself, usually taken to be a natural instinct, has proven to be an administered, constructed skill."s3 Seeing and looking can be misleading. Eyes do not have the power to communicate on their own. Further, the vulnerability of historical actors endures within the archive and in the scholarship that makes use of vulnerable bodies and their absentee stories. As Jane Nicholas asks, "what is our ethical duty to the dead?" and "can you be vulnerable to history and historical practices?" ${ }_{4}^{4}$ To the latter, the answer is an undeniable yes. The trauma of the Yemenite Jews in their emigration-consciously erased in the 1950s-also risks being lost in history if we take the mythology for granted. As for our ethical duty to the dead, we must remember that photographs are always representations. While this may seem a redundant or superfluous point, it is pivotal because it forces a consideration of what exactly the photographs are representing: do they represent the individ- 
uals? The event they are participating in? An ideology? What they represent hinges on their purpose and their function. Our duty is to question what is seemingly evident.

1

Dodah is Hebrew for aunt.

\section{2}

Leni Sonnenfeld, Eyes of Memory: Photographs from the Archives of Herbert and Leni Sonnenfeld (New Haven, CT: Yale University Press, 2004), 12.

3

Sonnenfeld, Eyes of Memory, vi.

4

Shabbat is the weekly Jewish holy day on Friday; a Bar Mitzvah is a Jewish coming-of-age celebration for boys at the age of thirteen.

\section{5}

Herbert S. Lewis, After the Eagles Landed: The Yemenites of Israel (Boulder, Colo.: Westview Press, 1989), 56.

\section{6}

Esther Meir-Glitzenstein, The "Magic Carpet" Exodus of Yemenite Jewry: An Israeli Formative Myth (Brighton: Sussex Academic Press, 2014), 2.

7

Reuben Ahroni, Jewish Emigration from the Yemen, 1951-98: Carpet Without Magic (Richmond, Surrey: Curzon, 2001), 1.

\section{8}

Meir-Glitzenstein, The "Magic Carpet" Exodus of Yemenite Jewry, 9.

9

Ashkenazi refers to Jews of European heritage.

\section{0}

Tudor Parfitt, The Road to Redemption: The Jews of the Yemen, 1900-1950 (Leiden: E.J. Brill, 1996), 180.

11 Meir-Glitzenstein, “Operation Magic Carpet," 150.

12

It was also published in The Washington Post six days later. See Ruth Gruber, "Jews Flee 'New Egypt' by Airlift," The Washington Post (1923-1954), Nov 13, 1949.

\section{3}

Meir-Glitzenstein, "Operation Magic Carpet," 155.

14

Parfitt, The Road to Redemption, 228.

\section{5}

Meir-Glitzenstein, "Operation Magic Carpet," 154.

16

Meir-Glitzenstein's “Operation Magic Carpet," 150.

17

Meir-Glitzenstein's “Operation Magic Carpet," 150.

18

Meir-Glitzenstein's "Operation Magic Carpet," 150.

19

Parfitt, The Road to Redemption, 174.

20

Parfitt, The Road to Redemption, 174.

21

Parfitt, The Road to Redemption, 217.

22

Noa Hazan, "The Racialisation of Jews in Israeli Documentary Photography," Journal of Intercultural Studies 31, no. 2 (2010): 163.

23

Hazan, "The Racialisation of Jews,"170.

\section{4}

Hazan, "The Racialisation of Jews,"170.

25

Hazan, “The Racialisation of Jews,"171.

26

Hazan,"The Racialisation of Jews,"174-5. 


\section{7}

Hazan, "The Racialisation of Jews,"180.

\section{8}

"Archives," Jewish Public Library, accessed 8 April 2019, http://www.jewishpubliclibrary.org/ en/archives/

\section{9}

Stoler, Along the Archival Grain, 20

\section{0}

Stoler, Along the Archival Grain, 22.

\section{1}

Stoler, Along the Archival Grain, 24.

\section{2}

Stoler, Along the Archival Grain, 32.

\section{3}

Stoler, Along the Archival Grain, 44.

\section{4}

Stoler, Along the Archival Grain, 47.

\section{5}

Stoler, Along the Archival Grain, 47.

\section{6}

Stoler, Along the Archival Grain, 45.

\section{7}

Michel-RolphTrouillot, Silencing the Past: Power and the Production of History (Boston: Beacon Press, 2015),25.

\section{8}

Trouillot, Silencing the Past, 49.

\section{9}

Trouillot, Silencing the Past,2.

40

Trouillot, Silencing the Past,25.

\section{1}

Trouillot, Silencing the Past, 26.

\section{2}

Trouillot, Silencing the Past, 52.

\section{3}

Regarding their collection associated with Operation Magic Carpet, the JDC's online photo archives are complete and contain every photo the JDC has of this event; Misha Mitsel, email, 12 February 2019.

\section{4}

"Yemenite girl; Operation Magic Carpet; NY_08405,"JDC Archives, accessed 8 April 2019, https://archives.jdc.org/our-collections/ photograph-collection/.

\section{5}

"Young Yemenite Jewish Refugee; NY_08405," JDC Archives, accessed 8 April 2019, https:// archives.jdc.org/our-collections/photograph-collection/

\section{6}

"Al Taylor: Morocco, Late 1940s," JDC Archives, accessed 8 April 2019, https://archives.jdc.org/project/al-taylor-morocco-late1940s/; Alexander Taylor Employment Card. Misha Mitsel, email, 12 February 2019.

\section{7}

"Al Taylor: Morocco, Late 1940s," JDC Archives.

\section{8}

Thomas Fensch, "The Journalist Who Knew Oskar Schindler: An Interview with Herbert Steinhouse," Oskar Schindler and His List: The Man, The Book, The Film, The Holocaust and Its Survivors (Forest Dale, Vermont: Paul S. Eriksson, 1995), 3-19.

\section{9}

schindlerjuden translates to Schindler's Jews.

\section{0}

Fensch, Oskar Schindler and His List, 3-19.

\section{1}

"Local Journalist Interviewed Oskar Schindler Just After War," Montreal Gazette, September 241996.

\section{2}

See Rother Fonds at Jewish Public Library; and see Herbert Steinhouse Fonds at Library and Archives Canada. http://data2.archives.ca/ pdf/pdf001/p000000741.pdf

\section{3}

Hazan, "The Racialisation of Jews,"180.

\section{4}

Jane Nicholas, "A Debt to the Dead? Ethics, Photography, History, and the Study of Freakery," Histoire Sociale/Social History 47, no. 93 (2014): 141. 